\title{
Effects of herbage allowance and animal factors on intake by grazing dairy cows
}

\author{
JL Peyraud 1, E Comeron 2, M Wade ${ }^{3}$ \\ IINRA, Station de Recherches sur la Vache Laitière, 35590 Saint-Gilles, France; 2INTA Estacion Exp Agrop \\ Rafaela, CC 22, 2300 Raela, Santa Fe; अFacultad Cs Vs, UNCPBA, Pinto 399 , \\ 7000 Tandil, Buenos Aires, Argentina
}

Sources of variation in herbage organic matter intake (HOMI) by grazing dairy cows are not well quantified. These two trials studied the effects of Herbage Allowance (HA) and cows characteristics upon HOMI.

In trial 1 (1988) two herbage allowances (HA) (Low and Medium, 19 and $26 \mathrm{~kg} \mathrm{OM} / \mathrm{cow} / \mathrm{d}$ ) were compared in a continuous design using two groups of five cows. In trial 2 (1989), three HA (Low, Medium and High, 19, 29 and $46 \mathrm{~kg}$ OM/cow/d) were compared in a $3 \times 3$ latin square design using three groups of five cows. Twenty five mid-lactating cows (six primiparous per trial) were used. Fat corrected milk (FCM) at turnout in April (Mpt) ranged between 17 to $35 \mathrm{~kg}$ and body live weight (LW) ranged between 510 to $680 \mathrm{~kg}$. The cows strip-grazed plots of vegetative Lolium perenne and did not receive concentrates. Measurements were realized on periods of 7-8 days on firs growth in may ( 3 periods for each trial) and on regrowths of 21 and 35 days (trial 1 only). HOMI was measured using chromic oxide to estimate faecal output and $N$ and ADF content in faeces to estimate digestibility (Peyraud et al, 1989, XVI International Grassland Congress, Nice, France, 1151-1152). Every fresh dung, marked by individual feeding different coloured plastic particles, was sampled on the field during five days. The pregrazing herbage mass (HM) was measured by cutting to ground level and $\mathrm{HA}$ was calculated as $H M \times O A$ where $O A$ is the daily offered area (m²/cow).
$\mathrm{HM}$ ranged from 3.5 to $7.1 \mathrm{t} \mathrm{OM} /$ ha but $\mathrm{OM}$ digestibility was fairly constant $(0.79$ to 0.82$)$. In trial 1, FCM production and HOMI tended to be reduced when allowance was low but differences failed to be significant. In tria! 2, FCM decreased linearly with HA. HOMI was depressed in Low HA but did not differ significantly between Medium and High HA. Significant HOMI variations between cows and between periods were always noted. From pooled data, HOMI was related to the daily $\mathrm{HA}$ and cows characteristics (HOMI $=7.2-0.952$ / $\mathrm{HA}+0.277 \mathrm{Mpt}+0.0081 \mathrm{LW}, \mathrm{n}=95, \mathrm{r}^{2}=0.60$, $\mathrm{rsd}=1.77 \mathrm{~kg}$ ). However, splitting $\mathrm{HA}$ in its two components, accounted for more of the variance in $\mathrm{HOMI}(\mathrm{HOMI}=-20.4-115 / \mathrm{OA}+$ $9.63 \mathrm{HM}-0.873 \mathrm{HM}^{2}+0.266 \mathrm{Mpt}+0.0094$ $L W, r^{2}=0.70, r s d=1.56 \mathrm{~kg}$ ). Therefore $\mathrm{HM}$ does have an independent effect upon HOMI. It may exist an optimum range of $\mathrm{HM}$ for intake perhaps because small swards and, at the opposite, tall lodged swards, would be difficult for the cow to prehend. HOMI increased by $266 \mathrm{~g} \mathrm{OM} / \mathrm{kg}$ milk which could account for the two thirds of the supplementary energy requirements. HOMI also increased according to $L W$ but no intrinsic effect of lactation number was detected.

Herbage intake is greatly affected by the level of milk production and herbage mass appears to be of great importance in determining the availability of the grass.

\begin{tabular}{lrrrrr} 
& \multicolumn{2}{c}{ trial 1 } & \multicolumn{2}{c}{ trial 2} & \\
\cline { 2 - 6 } & LHA & MHA & LHA & MHA & HHA \\
FCM $(\mathrm{kg} / \mathrm{d})$ & 20.6 & 22.0 & $20.4^{\mathrm{a}}$ & $21.7^{\mathrm{b}}$ & $23.0^{\mathrm{c}}$ \\
HOMI $(\mathrm{kg} / \mathrm{d})$ & 13.5 & 14.9 & $13.8^{\mathrm{a}}$ & $16.2^{\mathrm{b}}$ & $16.7^{\mathrm{b}}$ \\
\hline
\end{tabular}

Means with different superscripts differ at $P<0.01$. 